\title{
AOR
}

Selected Papers of \#AolR2020: The $21^{\text {st }}$ Annual Conference of the Association of Internet Researchers Virtual Event / 27-31 October 2020

\section{FROM USER GENERATED CONTENT TO A USER GENERATED AESTHETIC: INSTAGRAM, BRANDS AND THE APPROPRIATION OF DIGITAL PHOTOGRAPHY}

\author{
Liron Simatzkin-Ohana \\ Hebrew University of Jerusalem, Jerusalem, Israel \\ Paul Frosh \\ Hebrew University of Jerusalem, Jerusalem, Israel
}

In this paper we argue for a renewed critical examination of the overt and direct representational practices of commercial brands on social media, in particular their appropriation and adaptation of user-generated 'amateur' or 'vernacular' cultural styles. Without this renewed attention our understanding of the connections between social media and consumer culture are overly skewed towards indirect brand strategies such as the rise of influencers and self-branding. For instance, recent research has focused on Instagram as a key site for new visual formats and practices (Highfield \& Leaver, 2016; Manovich, 2017), including its importance in influencer culture (Abidin, 2016). Yet relatively little attention has been paid to the deliberate employment of user-generated photographic styles by brands themselves - to the 'vernacularization' of brand imagery. In this paper we outline the features of this process in recurring visual patterns, contextualize it in relation to earlier commercial appropriations of popular culture, and discuss its significance for cultural production in social media. We take fashion brands on Instagram as our case study for two reasons: first, fashion photography is strongly connected to overt professional stylization; second, fashion can be seen as structurally definitive of consumer society in general (Lipovetsky, 1994).

We analyzed of a corpus of photographic posts collected from the Instagram accounts of 24 fashion brands, selected based on lists of 'leading fashion brands' published annually by the business and financial press (e.g. Forbes and Fashion United). Only accounts exceeding an activity threshold of 300 posts and a popularity threshold (quarter of a million followers of US and European brands, 5,000 followers for Israeli brands) were included in the analysis. From each brand selected for analysis, all published posts were given an initial overall viewing, up to a cut-off date of 1st July 2018. This overall initial viewing enabled the gradual identification of recurring

Suggested Citation (APA): Simatzkin-Ohana, L., Frosh, P. (2020, October). From User Generated Content to a User Generated Aesthetic: Instagram, Brands and the Appropriation Of Digital Photography. Paper presented at AoIR 2020: The 21 $1^{\text {th }}$ Annual Conference of the Association of Internet Researchers.

Virtual Event: AolR. Retrieved from http://spir.aoir.org. 
vernacular patterns, resulting in a corpus of 90 posted photographs which were subjected to detailed analysis.

While eight distinctive patterns of stylistic appropriation were identified, here we discuss the three most common:

(1) Regramming: featuring a user's images in the company's official feed alongside professional images, and tagging the user as the image-creator. We discuss how the aspiration to be regrammed by a brand leads users to create 'brand-friendly' content. At the same time, regramming is a popular technological workaround or 'hack' to platform constraints on image-sharing: hence its very use by corporations connotes the 'user-generated' popularity and virality of the brand.

(2) Vernacular Celebrity: posting the 'amateur-looking' photographs of a celebrity associated with the brand. This pattern simultaneously promotes both sides of the celebrity paradox (Turner, 2004; Marwick \& Boyd, 2011a) - remoteness and accessibility - helping brands to gain authenticity while maintaining a conventional distinction between the brand's visual assets and those of 'regular users'.

(3) Brandfie: usually 'faceless' selfie-style images created by brands themselves where the brand appears to be the 'self' performing its own representation (Zhao \& Zappavigna, 2017). The brandfie presents the brand as a social subject through an overtly embodied gestural image (Frosh, 2015), integrating bodily, social and digital existence into a single format. Through 'brandfies', brands seem to achieve not just social but also physical being.

Overall, our project highlights the aesthetic vernacularization of brand images on social media and the adoption by brands of amateur styles associated with user-generated content. In the case of Instagram brand accounts, this adoption has solidified into a recognizable 'user-generated aesthetic'. This is a contrary but parallel process to the professionalization of non-professional users on social media (e.g. Kim, 2012; Lobato 2016; Cunningham, Craig and Silver, 2016). Together, these dual movements professionalizing user-generation and vernacularizing professional images - constitute a form of 'context collapse' that is more generally characteristic of social media (Marwick and Boyd, 2011b; Davis and Jurgenson, 2014), but here appears in visual form: as the collapse of conventional stylistic distinctions and visual indicators which viewers rely upon to infer an image's authorial status, milieu and purposes.

This context collapse conforms to the expansion of branding practices and discourses beyond the purview of marketing and celebrity into all aspects of social life (BanetWeiser, 2012; Marwick, 2015), and in particular to Instagram as a 'social media storefront' where 'sociality unfolds within platforms that encode marketplace logics' (Hund and McGuigan, 2019). If everyday practices of self-representation and communication (such as photography) on social media are already largely produced within the discursive and performative structures of marketing, their actual appropriation by marketing and branding companies is likely to be both ideologically seamless and generative of new content.

Under these conditions, the activities of users and brands may 'collude' to the point where it becomes hard - or even experientially irrelevant - to differentiate between their 
modes of action and expression. In an arena where users practice self-branding, and brands perform private life, engage in social interactions, and present emotional and physical selves, what signifies the difference between the two?

\section{References}

Abidin, C. (2016). Visibility labour: Engaging with Influencers' fashion brands and \#OOTD advertorial campaigns on Instagram. Media International Australia 161(1) 86100

Banet-Weiser, S. (2012). Authentic ${ }^{\mathrm{TM}}$ :The Politics of Ambivalence in a Brand Culture. New-York: New York University Press

Cunningham, S. Craig D. \& Silver, J. (2016). YouTube, Multichannel Networks and the Accelerated Evolution of the New Screen Ecology. Convergence: The International Journal of Research into New Media Technologies, 22(4), 376-391

Davis, J. L. \& Jurgenson, N. (2014). Context collapse: theorizing context collusions and Collisions. Information, Communication \& Society, 17(4), 476-485

Frosh, P. (2015). The Gestural Image: The Selfie, Photography Theory, and Kinesthetic Sociability. International Journal of Communication 9, 1607-1628

Highfield, T. \& Leaver, T. (2016). Instagrammatics and digital methods: studying visual social media, from selfies and GIFs to memes and emoji. Communication Research and Practice 2(1), 47-62

Hund, E. \& McGuigan, L. (2019). A Shoppable Life: Performance, Selfhood, and Influence in the Social Media Storefront. Communication Culture \& Critique, 12(1), 18-35

Kim, J. (2012). The Institutionalization of Youtube: From User-Generated Content to Professionally Generated Content. Media Culture \& Society, 34(1), 53-67

Lipovetsky, G. (1994). The Empire of Fashion: Dressing Modern Democracy. New Jersey: Princeton University Press

Lobato, R. (2016). The cultural logic of digital intermediaries: YouTube multichannel networks. Convergence: The International Journal of Research into New Media Technologies. 22(4) 348-360

Manovich, L. (2017). Instagram and Contemporary Image. Self-published. http://manovich.net/index.php/projects/instagram-and-contemporary-image

Marwick, A. E., \& boyd, d. (2011a). To See and Be Seen: Celebrity Practice on Twitter. Convergence: The International Journal of Research into New Media Technologies. 17(2), 139-158 
Marwick, A. E., \& boyd, d. (2011b). I tweet honestly, I tweet passionately: Twitter users, context collapse, and the imagined audience. New Media \& Society. 13(1), 114-133.

Marwick, A. (2015). Instafame: Luxury Selfies in the Attention Economy. Public Culture, $27(1(75)), 137-160$

Turner, G. (2004), Understanding Celebrity. London: Sage.

Zhao, S. \& Zappavigna, M. (2017). Beyond the Self: Intersubjectivity and the Social Semiotic Interpretation of the Selfie. New Media \& Society. 20(5), 1735-1754 